\title{
An Assessment of Indoor Acoustic Condition in Students Hostels within Obafemi Awolowo University, Nigeria
}

\author{
Bode Abiodun Orola*, Sunday Aderemi David \\ Department of Architecture, Obafemi Awolowo University, Nigeria \\ Email: *ol abode.abiodun30@gmail.com, davidsaderemi@gmail.com
}

How to cite this paper: Orola, B.A. and David, S.A. (2019) An Assessment of Indoor Acoustic Condition in Students Hostels within Obafemi Awolowo University, Nigeria. Open Journal of Acoustics, 9, 13-25. https://doi.org/10.4236/oja.2019.92002

Received: February 26, 2019

Accepted: May 7, 2019

Published: May 10, 2019

Copyright $\odot 2019$ by author(s) and Scientific Research Publishing Inc. This work is licensed under the Creative Commons Attribution International License (CC BY 4.0).

http://creativecommons.org/licenses/by/4.0/

\section{(c) (i) Open Access}

\begin{abstract}
It has been hypothesized that objective assessment for building acoustic conditions only may not always be representative of the users' perception in occupied indoor spaces. This study objectively and subjectively examined indoor acoustic condition in rooms within students' hostels in Obafemi Awolowo University, Nigeria. The objective assessment considered the physical measurement of sound pressure level in the rooms in relation to the rooms' physical characteristics like window to external wall area and window to floor area ratios. The subjective assessment considered the occupants' perception of the acoustic condition in the rooms in relation to their personal characteristics like age, gender, body mass index, metabolic rate, and body skin area. The sound pressure level was measured in each of the randomly selected 44 rooms at 15 minute intervals between 7 hours and 19 hours daily through a period of eight weeks. The measurement was done with High Accuracy Digital Sound Noise Level Data Loggers placed at work plane at the centre of the rooms. The geometry of the rooms was documented through physical measurements. All the occupants of the selected rooms as well as the two adjoining rooms, amounting to 696 respondents, were purposively selected to fill a questionnaire regarding activities carried out in the rooms, the frequency of fenestration opening, the personal characteristics of the occupants and the rooms' occupancy ratio. This study established a strong correlation between the objective and subjective assessments of the acoustic condition in the spaces. Moreover, out of all the occupants' personal characteristics considered, it was the age that has a relationship with the occupants' perception of the acoustic condition that is closest to significant level.The relationship between their perception and measured sound pressure level was slightly more pronounced among the male gender than the female with correlation coefficients of 0.115 and 0.096 respectively. This study concluded that none of
\end{abstract}


the considered occupants' personal characteristics can effectively predict their response to indoor acoustic condition in the spaces.

\section{Keywords}

Acoustic Condition, Sound Pressure Level, Personal Characteristics, Occupants' Perception, Objective And Subjective Assessments

\section{Introduction}

It has been established that the indoor acoustic condition is one of the main factors that determine the quality of the indoor environment in general (Bluyssen, 2010) [1]. Therefore, it is strongly related to the performance, comfort, and health of occupants of indoor spaces within the built environment. An indoor space with acceptable acoustic environment is one that can control excess noise pollution from both indoor and outdoor sources. Hence, acoustic comfort has been defined as a state of contentment with acoustic conditions. Furthermore, the acoustic condition has been defined by ISO 12913-1 (2014) [2] as the acoustic environment as perceived or experienced, and/or understood by a person or people, in context. This identified with a robust definition by Rasmussen and Rindel (2005) [3]. The study remarked that acoustic comfort is a concept that can be characterized by the absence of unwanted sound, desired sounds with the right level and quality, opportunities for acoustic activities without annoying other people.

The acoustic condition is however mostly associated in engineering to only sound pressure levels low enough not to cause discomfort or annoyance (Nikolaos-Georgios Vardaxis et al., 2018) [4]. Hence, many scholars assessed it purely through objective measurements in laboratories and not in the field where occupants in the built environment experience real life situations (Osasona et al., 2011 [5]; Kim et al., 2013 [6]; Spah et al., 2013 [7] and Kylliainen et al., 2016 [8]). However, studies have shown that the use of only objective assessment for building acoustic conditions may have limited potentials in guiding building design. This is because it may not always be representative of the perception of users of occupied indoor spaces (Ljunggren et al., 2014) [9]. This, therefore, suggests that a synergy between objective and subjective assessment may produce more credible results to improve on available standards and to accurately predict the responses of occupants of indoor spaces.

The quality of the acoustic environment is linked to numerous physical parameters, which include both the physical properties of sound itself and the physical properties of the indoor space (Osasona, et al., 2011 [5]; Vermeir and Van der Bergh, 2003 [10]; Iordache et al., 2013 [11]). Sound is characterized by the sound pressure level in a short-term and long-term period and by sound frequency. The acoustic environment is influenced by such physical room properties as sound insulation, absorption and reverberation time (Frontczak, and 
Wargocki, 2011) [12]. Generally, acoustic comfort assessments are based on some objective acoustic models. Fundamental to the models is the reverberation time which is the time required for the sound pressure level in a room to decrease by $60 \mathrm{~dB}$ after being stopped at the emission source (Harris and Shade, 1994 [13]; Jian, 2006 [14]).

There are many other models used in various acoustic comfort studies with their different strength and weaknesses. First is the Geometric model which assumes that the rays leave evenly acoustic source mirroring the environment. This leads to reflections and every surface that the rays come in contact will suffer attenuation. The acoustic ray theory is based on the idea that sound is propagated in the form of a ray, with properties similar to those found in the geometrical optics (Gerges, 2000) [15]. Such assumption may only be reliable when the wavelength is extremely smaller than the dimensions of the room where it occurs. Hence geometric model evaluations may not be satisfactory at low frequencies (Vieira and de Sousa Costa, 2012) [16].

Second is the Image-Source model which treats each sound reflection as a virtual source, which is out of the environment and consists of the source image, across the wall. According to Vieira and de Sousa Costa, (2012) [16], it is the most commonly used model in rectangular environments such as schools, offices and homes. However, it does not take into account the diffusion effects of reflections or mirroring caused by irregular surfaces. The third is the Ray-Tracing model which takes into account the diffuse reflections and requires a computational time only proportional to the length of the impulse response, but does not provide results with good temporal resolution (Vieira and de Sousa Costa, 2012) [16].

Other acoustic quality models include Speech Privacy index which is mainly applied for open plan offices and relates to the degree of speech disturbance between two individuals who are not in conversation with each other; Speech Intelligibility index which evaluates the degree of understanding or non-understanding of speech in rooms; and Articulation Index which is a signal-to-noise ratio assessment and reflects the degree to which intruding speech contents, from adjacent work stations, exceeds the ambient sound pressure level at the listener's ear in an indoor space (Osasona et al., 2011 [5]; Andersson and Chigot, 2004 [17]).

In recent times, however, the instrumentation for the measurements and evaluation of acoustic quality has been aided by development within the field of sound recording as well as the development of laptops (Andersson and Chigot, 2004) [17]. Moreover, Horrall, Pirn, and Markham, (2003) [18] concluded that a portable computer with integrated soundboard and a suitably amplified loudspeaker and test microphone are all that are needed to perform in-situ measurements of Articulation Index or other accepted indices. In line with this, Andersson and Chigot, (2004) [17] remarked that such instrumentation allows technicians to survey a large number of working places economically. There are cost efficient tools meeting the requirements for testing in most common environments where oral privacy is likely to be required. In view of the foregoing, this 
study employed the use of sound level data logging instruments in conjunction with relevant computer software to objectively assess the acoustic quality in relation to the overall indoor environmental quality in indoor spaces within the study area.

Much of studies regarding the assessment of the acoustic condition within the built environment has been done either at the urban scale or in non-domestic buildings like worship centres, learning and teaching environment as well as care facility centres (Astolfi and Pellerey, 2008 [19]; Ana et al., 2009 [20]; Osasona et al., 2011 [5]; Yilmazer and Acun, 2018 [21]; Aletta et al., 2018 [22]). Some of the studies carried out in domestic buildings, including residences, were mostly done within a context far different from the ones existing in residential neighbourhoods in Africa as a whole and in Nigeria in particular (Nikolaos-Georgios Vardaxis et al., 2018 [4]). This is noteworthy because it has been established that occupants' response to aspects of the indoor environment is linked to their personal and socio-cultural characteristics, and that this relationship has not been adequately examined (Frontczak and Wargocki, 2011 [12]). This is further corroborated by the definition of acoustic condition according to ISO 12913-1 (2014) [2], which emphasized the "context" of its assessment or perception.

The main aim of this study was, therefore, to assess the acoustic condition in the rooms within occupied student's hostels in Obafemi Awolowo University, Ile-Ife, Nigeria both objectively and subjectively. The peculiarity of this context is evident in its location and the primary task for which the rooms were designed. First, the spaces were sleeping cum reading rooms within the campus of a University community. They do not require an acoustic condition exactly the same with that expected of a classroom or a library, but still need an acoustic condition acceptable for reading while carrying out other domestic activities within the same space. Second, the spaces were largely occupied by occupants form a socio-cultural background whose perception has not received adequate examination in acoustic comfort studies (Nikolaos-Georgios Vardaxis et al., 2018 [4]). Hence, the specific objectives of this study were first, to examine measured sound pressure level in the hostel rooms in relation to the physical characteristics of the rooms. Third, examine the occupants' perception of the acoustic condition in the rooms in relation to their personal characteristics. At last, analyse the relationships between the two.

\section{The Study Area}

The studied student hostels are within the campus of Obafemi Awolowo University which is located within Ile-Ife, a small city in South-western Nigeria located between latitudes $7^{\circ} 28^{\prime} \mathrm{N}-7^{\circ} 34^{\prime} \mathrm{N}$ and longitudes $4^{\circ} 27^{\prime} \mathrm{E}-4^{\circ} 35^{\prime} \mathrm{E}$ with an elevation of about $275 \mathrm{~m}$ above sea level. There are nine main hostel buildings within the neighbourhood with a combined capacity of 10,344 students. These are the Murtala Mohamed Post-graduate hall, Adekunle Fajuyi hall, Moremi hall, La- 
doke Akintola hall, Alumni hall, ETF hall, Angola hall, Awolowo hall, and Mozambique hall.

Each hostel building has study cum sleeping rooms as the main spaces with other ancillary spaces like kitchenettes, bathrooms and laundry at one end of each of the block of rooms. Observation revealed that the walls are of sandcrete blocks rendered on both sides with cement and sand plaster, and painted with matte finish. The windows are made of glass louver to achieve natural ventilation. With the exception of Angola and Mozambique halls which have ceiling fans installed in all the rooms, the rooms within most of the hostel buildings were designed with no mechanical ventilation system. Their doors are timber flush doors. The roofs are made of corrugated asbestos with asbestos ceiling. Among different design and layout features characterizing the different hostel buildings which might influence the quality of the acoustic environment in the spaces areterraces and balconies, as well as vegetation and green spaces that serve as a buffer from street noise (Zhao et al., 2009 [23]; Dzhambov and Dimitrova, $2014[24])$.

\section{Material and Methods}

The indoor sound pressure level in the selected rooms was measured with DT-173 High Accuracy Digital Sound Noise Level Data Loggers shown in Plate 1 with a measuring range of $30 \mathrm{~dB}$ to $130 \mathrm{~dB}$ and data memory of 129,920 samples. It has a dynamic range of $50 \mathrm{~dB}$, a frequency range of $31.5 \mathrm{~Hz}$ to $8 \mathrm{kHz}$, and an accuracy of $+/-1.4 \mathrm{~dB}$. The data loggers were connected to Personal Computers (PC) and placed at work plane (1.0 m above the finished floor level) at the center of the selected rooms. The data was taken in each of the rooms at 15-minute intervals between $07 \mathrm{hrs}$ and $19 \mathrm{hrs}$ daily through a period of eight weeks altogether spanning between the month of February and July, 2018. The data was then downloaded into PC using the sound data logger application software for analysis.

Selected rooms for measurements were 44 in all. These were randomly selected such that at least four rooms represented each of the nine main room layout types identified within the students' hostels. All the selected rooms have the same wall, window and ceiling material finishes. The geometry of the rooms was documented through physical measurement using measuring tape. This was used to generate data on the window area, the wall area, the floor area, the window to floor area ratio and the window to wall area ratio. Data regarding the floor area per occupant in each room was also collected for it determines the amount of sound absorbing furniture in each room. All the occupants in the selected rooms, as well as the two adjoining rooms, were purposively selected to fill a questionnaire. This amounted to 696 respondents. The questionnaire elicited information regarding the activities carried out in the rooms and the frequency at which occupants opened the fenestrations. The same questionnaire was used to capture other data about the occupants' gender, age and complexion, as well 


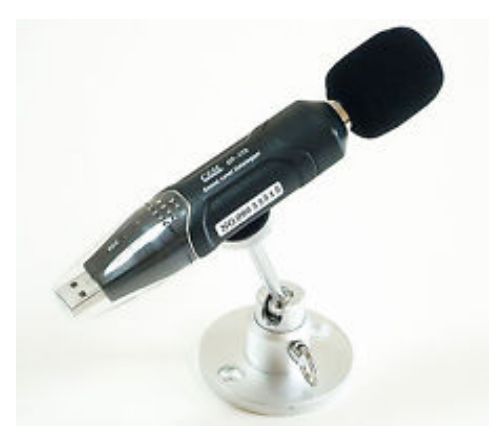

Plate 1. DT-173 High accuracy digital sound noise level data logger.

as the occupants' perception of the acoustic condition in the rooms. Other personal characteristics like weight and height were measured using Generic height and weight scale. These were used to calculate the Body Mass Index (BMI), the Body Metabolic Rate (BMR), and the Body Skin Area (BSA). The BMI was calculated using Equation (1) (United States Department of Health and Human Services); the BMR was calculated using Equations (2a) and (2b) for male and female respectively (Frankenfield, Roth-Yousey and Compher, 2005 [25]); while the BSA was calculated using Equation (3) (Farlex Partner Medical Dictionary, $2012[26])$.

$$
\begin{gathered}
\text { Body Mass Index }=\text { Weight }(\mathrm{kg}) / \text { square of the height }(\mathrm{m}) \\
655+\{4.35 \times \text { weight }(\text { pounds })\}+(4.7 \times \text { height }(\text { inches })-4.7 \times \text { age }(\text { years })) \\
66+\{6.23 \times \text { weight }(\text { pounds })\}+(12.7 \times \text { height }(\text { inches })-6.8 \times \text { age }(\text { years })) \\
0.202 \times \text { weight } 0.425(\mathrm{~kg}) \times \text { height } 0.725(\mathrm{~m})
\end{gathered}
$$

Each respondent was asked to indicate the most prominent indoor and outdoor noise source and to rank the extent to which they were satisfied with the acoustic condition in the room. The data collected were subjected to statistical analysis using the IBM SPSS Statistics 22 . The mean measured sound pressure levels in each room layout type were objectively assessed with the standards according to the Nigerian Federal Environmental Agency (FEPA, 1990 [27]). The Agency stipulated that maximum permissible exposure limit for indoor acoustic comfort is $90 \mathrm{~dB}$ within an eight-hour period, and the exposure to impulsive or impact noise should not exceed $140 \mathrm{~dB}$. Further analysis was also carried out to determine which of the physical characteristics of the rooms can best predict the sound pressure levels. Furthermore, a regression analysis was carried out to determine which of the occupants' personal characteristics can best predict their perception of the acoustic conditions in the rooms.

\section{Results}

Physical measurement revealed that the nine different room layouts studied have window to floor area ratio that ranged from 0.08 to 0.52 . Their window to ex- 
ternal wall area ratio ranged from 0.08 to 1.01 , with $35.7 \%$ of the respondents occupying the room layout type that has the lowest window to floor ratio and window to external wall ratio of 0.08 .

Out of the 696 administered questionnaires, 576 were returned. After the questionnaires were sorted however, 462 were usable for the analysis resulting in a $66.38 \%$ response rate. All the respondents were either undergraduate or postgraduate students in the University with $62.8 \%$ being males while $37.2 \%$ were females. The Body Mass Index (BMI) distribution of respondents showed that $67.3 \%$, fell within normal range of 18.5 and 25 , while $30.9 \%$ were either under-weight or over-weight, and $1.8 \%$ were obese. Regarding the metabolic rate (BMR), $57.6 \%$ of the respondents were having metabolic rates between 58.33 and $75 \mathrm{kcal} /$ hour, $38.7 \%$ were below that range, while $3.8 \%$ were above the range. Regarding the Body Skin Area (BSA), $43.9 \%$ of the respondents were within the average range of between $1.7 \mathrm{~m}^{2}$ and $2.0 \mathrm{~m}^{2}, 52.5 \%$ were below the range, while $3.6 \%$ were above the range. Moreover, only $9.8 \%$ of the respondents were not adult (below 18 years of age), while a majority $61.8 \%$ were between ages 18 and 23 years.

The mean measured sound pressure levels in each room layout ranged from $27.75 \mathrm{dBA}$ to $56.29 \mathrm{dBA}$, with an overall mean value of $48.77 \mathrm{~dB}$. The highest measured sound pressure level during the entire study period was far lower than $90 \mathrm{~dB}$ which was the maximum allowable limit value according to FEPA (1990) [27], Figure 1 and Figure 2 show the average distribution of the mean measured sound pressure level during the day in the room layouts with the lowest window to external wall area ratio and the highest window to external wall area ratio respectively.

This study found that the main contributors to indoor sound pressure levels in the spaces as rated by the occupants were indoor noise sources. Furthermore, Table 1 and Table 2 revealed the contributions of different identified external and internal noise sources to the acoustic environment of the spaces as rated by the occupants. Table 1 showed that $76 \%$ of the occupants regarded roommates chatting as the most prominent indoor sound source, followed by noise from electronic gadgets, while Table 2 showed that $54.1 \%$ of the occupants regarded noise from people walking along the adjoining corridor as the most prominent outside noise source followed by activities in the hostel common room. This is similar to Wang and Jan (2014) [28], who found that the highest percentage of occupants rated "talking within the space" as the most prominent source of noise affecting them. Moreover, as shown in Table 3, only $9 \%$ of the occupants were dissatisfied with the mean sound pressure levels in the spaces.

\section{Discussions}

This study established a strong correlation between the objective and subjective assessments of the acoustic condition in the spaces. The objective analysis revealed that the mean measured sound pressure levels in the nine room layouts 


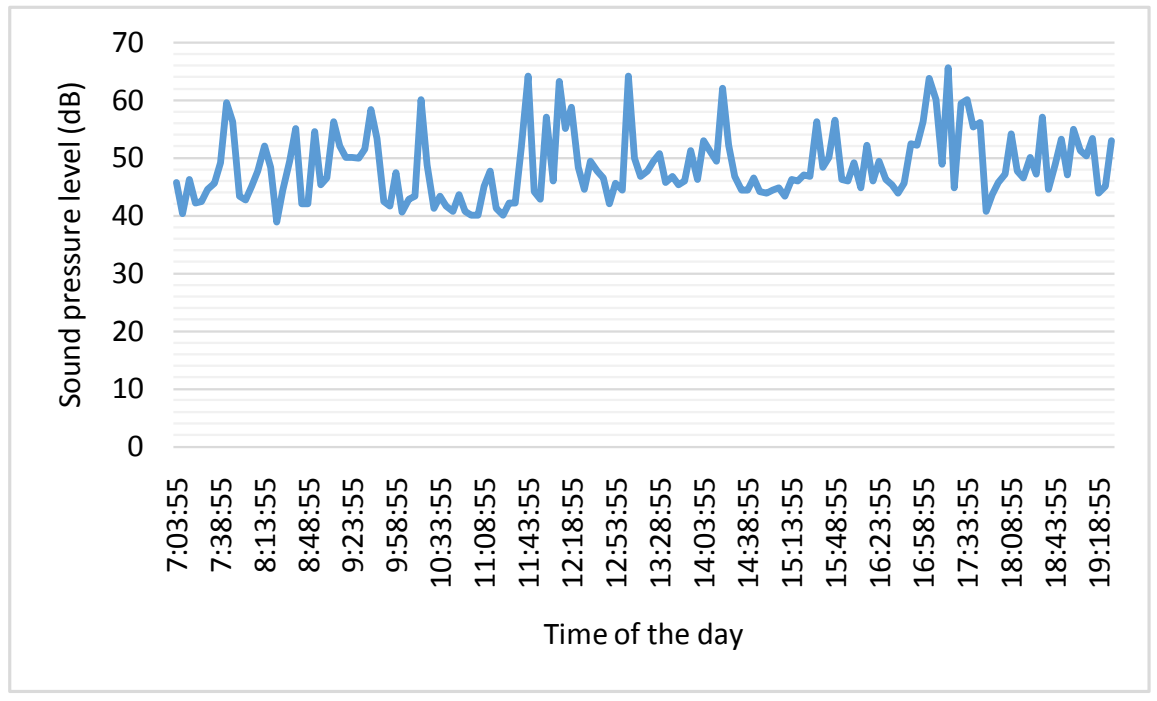

Figure 1. Mean measured sound pressure levels in the room layout with the lowest window to external wall area ratio.

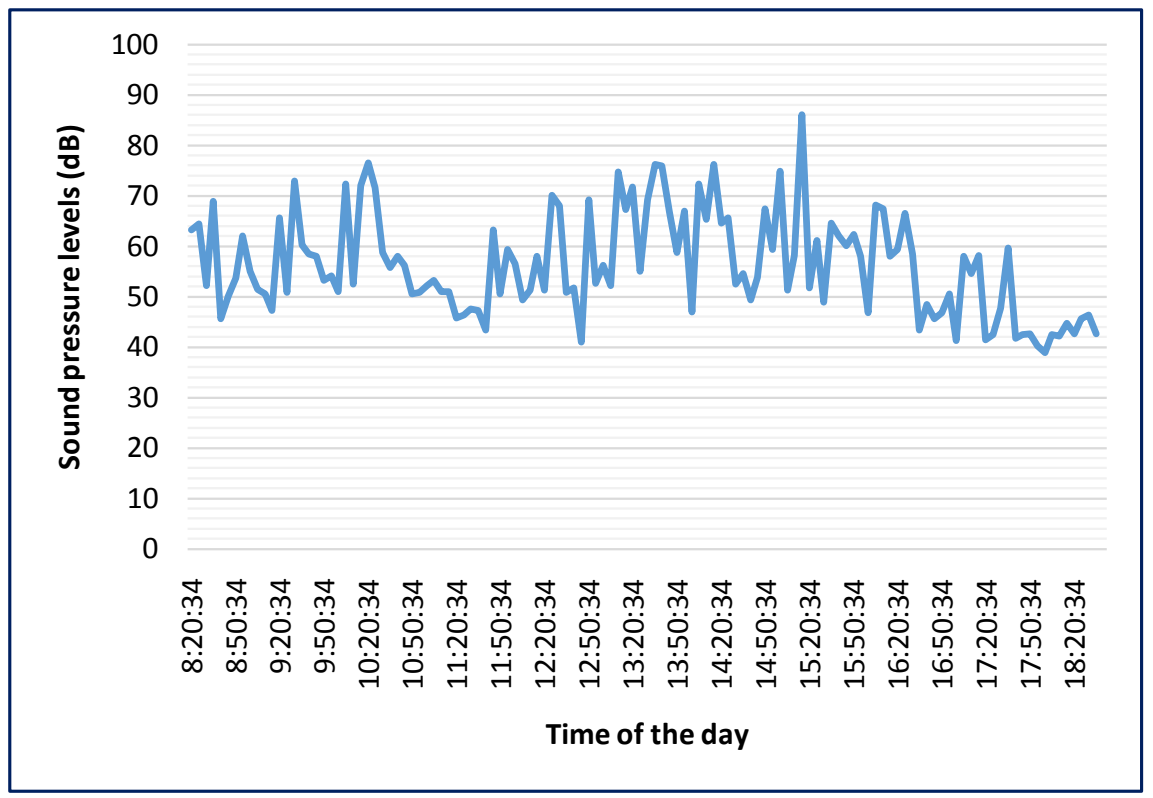

Figure 2. Mean measured sound pressure levels in the room layout with the highest window to external wall area ratio.

were less than the maximum allowable in the spaces by between $37.46 \%$ and $69.17 \%$. This showed that the entire room layout met the recommended standard in Nigeria, and hence should provide significantly high level of acoustic comfort. This was confirmed by the subjective assessment by the occupants which revealed that over $80 \%$ of the occupants were satisfied with the acoustic condition in the spaces. This showed that objective measurements could be effectively used to predict responses of occupants to acoustic conditions in the students' hostels.

Further analysis revealed a direct significant relationship between the mean measured sound pressure levels and the window to floor area, as well as with the 
Table 1. Most prominent indoor noise sources in the spaces.

\begin{tabular}{cccc}
\hline & Frequency & Valid Percent & Cumulative Percent \\
\hline none & 16 & 3.5 & 3.5 \\
roommates chatting & 346 & 76.0 & 79.6 \\
door slamming & 25 & 5.5 & 85.1 \\
noise from electronic gadgets & 57 & 12.5 & 97.6 \\
phone calls & 11 & 2.4 & 100.0 \\
Total & 455 & 100.0 & \\
\hline
\end{tabular}

Table 2. Most prominent outside noise source in the spaces.

\begin{tabular}{cccc}
\hline & Frequency & Valid Percent & Cumulative Percent \\
\hline none & 14 & 3.1 & 3.1 \\
religious activity & 33 & 7.4 & 10.5 \\
sporting activity & 34 & 7.6 & 18.1 \\
common room activities & 99 & 22.1 & 40.3 \\
people walking along the corridor & 242 & 54.1 & 94.4 \\
traffic noise & 8 & 1.8 & 96.2 \\
power generator & 16 & 3.6 & 99.8 \\
noise from next room & 1 & .2 & 100.0 \\
Total & 447 & 100.0 & \\
\hline
\end{tabular}

Table 3. Occupants' perception of the indoor sound pressure level.

\begin{tabular}{cccc}
\hline & Frequency & Valid Percent & Cumulative Percent \\
\hline neutral & 232 & 52.1 & 52.1 \\
slightly high & 173 & 38.9 & 91.0 \\
too high & 40 & 9.0 & 100.0 \\
Total & 445 & 100.0 & \\
\hline
\end{tabular}

window to external wall area ratios of the spaces both at $\rho<0.01$. This showed that the higher the ratios, the higher the measured sound pressure level. However, the correlation coefficient was higher for the window to external wall area ratio (0.45) than that for the window to floor area ratio (0.36). WhileShield and Dockrell (2004) [29]could not arrive at a conclusive confirmation for such relationship, several other studies like Aasvang et al. (2008) [30] carried out in bedrooms exposed to railway noise, and Tong et al. (2015) [31] carried out in unoccupied test rooms, established similar relationship between indoor sound levels with building characteristics related to the widow area and type. This suggests that direct relationship between indoor sound pressure levels and building characteristics related to window sizes exists in different outdoor/indoor acoustic context within which a building is located. 
Furthermore, according to Frontczak and Wargocki, (2011) [12] little is known regarding the potential influence of building type (which include their physical characteristics) on acoustic comfort of occupants in indoor spaces. However, studies like Leder et al. (2015) [32] and Sakellaris et al. (2016) [33] suggests that the floor area is strongly related to occupants' satisfaction with the acoustic environment. In fact, Leder et al. (2015) [32] concluded that satisfaction with acoustics and privacy was most strongly affected by workstation size and office type. While this study did not establish an exactly similar relationship, it, however, found an inverse relationship at a statistically significant level (correlation coefficient of -0.102) between the floor area per occupant and the measured sound pressure level. Which means the higher the floor area per occupant the lower the measured sound pressure level is. This, therefore, shows that the relationship between the building characteristics and the quality of the acoustic environment is evidently significant not only in offices but also in residencies like students' hostels.

The relationship between the perception of the occupants regarding the acoustic condition in the spaces and some of their personal characteristics were analysed. The personal characteristics considered were their gender, age, Body Mass Index, Body Metabolic Rate and their Body Skin Area. Analysis revealed that it is the occupant's age that had a relationship closest to the significant level with the occupants' perception of acoustic condition as measured by the sound pressure level. It was an inverse relationship, which showed that the higher the occupant's age, the better their level of satisfaction with the acoustic condition. No other personal characteristics considered have relationship close to significant level with their perception of indoor acoustic condition. This is similar to the findings of Sakellaris et al. (2016) [33] Moreover, a regression analysis showed that a change in the age among occupants between ages 21 and 23 years, as well as in the metabolic rate among occupants with less than $58.33 \mathrm{kcal} / \mathrm{hr}$. are statistically significant in predicting the occupants' perception of indoor acoustic condition. The former was however more significant.

Although Frontczak and Wargocki (2011) [12], remarked that very few studies provided convincing evidence regarding the impact of personal characteristics of occupants on level of satisfaction with indoor conditions, the findings of the few available studies were not totally the same with that of this study. While Kim et al. (2013) [34] gave evidence of gender differences in noise level and sound privacy satisfaction, Sakellaris et al. (2016) [33] showed that the relationship between indoor comfort and noise was higher among the male gender than the female, and that age was a significant determinant of occupants' perception of the acoustic environment. Although this study found no statistically significant relationship between occupants' gender and their perception of the indoor acoustic condition, it, however, found that the relationship between their perception and measured sound pressure level was slightly more pronounced among the male gender than the female with correlation coefficients of 0.115 and 0.096 respectively. However, Kim et al. (2013) [6] and Sakellaris et al. (2016) 
[33] along with most others with similar conclusion were carried out within office environment with specified tasks, and occupants age distribution far different from those in this study. This may account for the difference in the findings of this study.

\section{Conclusion}

This study established a significant correlation between the objective and subjective assessments of the indoor acoustic condition using measured sound pressure level in the rooms within the students' hostels. This showed that physical measurements of indoor sound pressure levels in the rooms can be used to effectively predict occupants' perception of the indoor acoustic condition in the spaces. It also showed that physical characteristics of indoor spaces are major determinants of their acoustic condition. Moreover, out of all the occupants' personal characteristics considered, it was only the age that has a relationship with their perception of measured indoor sound pressure level closest to a level that is statistically significant (with correlation coefficient of -0.04). This study concluded that none of the considered occupants' personal characteristics can effectively predict their response to indoor acoustic condition in the spaces. However, because of the very close age distribution of the respondents, this relationship may have to be further explored among respondents with wider age distribution exposed to the same range of indoor sound pressure level. It may also be expedient for future research to carry out similar study among respondents with more varied personal characteristics.

\section{Conflicts of Interest}

The authors declare no conflicts of interest regarding the publication of this paper.

\section{References}

[1] Bluyssen, P.M. (2010) Towards New Methods and Ways to Create Healthy and Comfortable Buildings. Building and Environment, 45, 808-818. https://doi.org/10.1016/j.buildenv.2009.08.020

[2] ISO 12913-1 (2014) Acoustics-Soundscape Part 1: Definition and Conceptual Framework.

[3] Rasmussen, B. and Rindel, J.H. (2005) Concepts for Evaluation of Sound Insulation of Dwellings-From Chaos to Consensus? Forum Acusticum, Budapest, $29 \mathrm{Au}-$ gust-2 September 2005, 1-12.

[4] Vardaxis, N.-G., Bard, D. and Waye, K.P. (2018) Review of Acoustic Comfort Evaluation in Dwellings-Part I: Associations of Acoustic Field Data to Subjective Responses from Building Surveys. Building Acoustics, 25, 151-170. https://doi.org/10.1177/1351010X18762687

[5] Osasona, O., Fisusi, A.A., Osasona, C.O., Onabanjo, B.O. and Yusuf, T.K. (2011) Speech Intelligibility of Lecture Theatres in Obafemi Awolowo University, Ile-Ife, Nigeria. Ife Journal of Technology, 20, 25-33.

[6] Kim, J.H., Ryu, J.K. and Jeon, J.Y. (2013) Effect of Temporal Decay on Perception of 
Heavy-Weight Floor Impact Sounds. The Journal of the Acoustical Society of America, 134, 2730-2738. https://doi.org/10.1121/1.4818743

[7] Späh, M., Hagberg, K., Bartlomé, O., Weber, L., Leistner, P. and Liebl, A. (2013) Subjective and Objective Evaluation of Impact Noise Sources in Wooden Buildings. Building Acoustics, 20, 193-213. https://doi.org/10.1260/1351-010X.20.3.193

[8] Kylliäinen, M., Oliva, D. and Rekola, L. (2016) A Laboratory Listening Experiment on Subjective and Objective Rating of Impact Sound Insulation of Concrete Floors. In: INTER-NOISE and NOISE-CON Congress and Conference Proceedings, Vol. 253, No. 7, Institute of Noise Control Engineering, USA, 1403-1411.

[9] Ljunggren, F., Simmons, C. and Hagberg, K. (2014) Correlation between Sound Insulation and Occupants' Perception-Proposal of Alternative Single Number Rating of Impact Sound. Applied Acoustics, 85, 57-68. https://doi.org/10.1016/j.apacoust.2014.04.003

[10] Vermeir, G. and Van den Bergh, J. (2003) Classroom Acoustics in Belgian Schools: Requirements Analysis, Design. International Congress and Exposition on Noise Control Engineering, Dearborn, 19-21 August 2002, 869-875.

[11] Iordache, V., Catalina, T. and Cucu, B.M. (2013) Experimental Investigation of the Reverberation Time Inside a Complex Geometry Indoor Space. Romanian Journal of Acoustics and Vibration, 10, 109-114.

[12] Frontczak, M. and Wargocki, P. (2011) Literature Survey on How Different Factors Influence Human Comfort in Indoor Environments. Building and Environment, 46, 922-937. https://doi.org/10.1016/j.buildenv.2010.10.021

[13] Harris, C.M. and Shade, N.T. (1994) Noise Control in Buildings. The Journal of the Acoustical Society of America, 96, 1217-1218. https://doi.org/10.1121/1.411328

[14] Jian, K.A.N.G. (2006) Acoustic Quality in Non-Acoustic Public Buildings. Technical Acoustics, 6, 513-522.

[15] Gerges, S.N.Y. (2000) Ruído: Fundamentos e Controle. 2nd Edition, NR Colsultoria e Treinamento, Florianópolis, 700 p.

[16] Vieira, G.F. and de Sousa Costa, E. (2012) Acoustic Evaluation of the School Environment: Measurement and Simulation. In: ABCM Symposium Series in Mechatronics, ABCM, Rio de Janeiro, Vol. 5, 889.

[17] Andersson, N.A. and Chigot, P. (2004) Is the Privacy Index a Good Indicator for Acoustic Comfort in an Open Plan Area? In INTER-NOISE and NOISE-CON Congress and Conference Proceedings, Vol. 2, Institute of Noise Control Engineering, USA, 4312-4319.

[18] Horrall, T., Pirn, R. and Markham, B. (2003) Instrumentation for Measuring Speech Privacy in Rooms. The Journal of the Acoustical Society of America, 114, 2305-2306. https://doi.org/10.1121/1.4780900

[19] Astolfi, A. and Pellerey, F. (2008) Subjective and Objective Assessment of Acoustical and Overall Environmental Quality in Secondary School Classrooms. The Journal of the Acoustical Society of America, 123, 163-173. https://doi.org/10.1121/1.2816563

[20] Ana, G.R., Shendell, D.G., Brown, G.E. and Sridhar, M.K.C. (2009) Assessment of Noise and Associated Health Impacts at Selected Secondary Schools in Ibadan, Nigeria. Journal of Environmental and Public Health, 2009, Article ID: 739502. https://doi.org/10.1155/2009/739502

[21] Yilmazer, S. and Acun, V. (2018) A Grounded Theory Approach to Assess Indoor Soundscape in Historic Religious Spaces of Anatolian Culture: A Case Study on Hac1 Bayram Mosque. Building Acoustics, 25, 137-150. 
https://doi.org/10.1177/1351010X18763915

[22] Aletta, F., Vander Mynsbrugge, T., Van de Velde, D., De Vriendt, P., Thomas, P., Filipan, K., Devos, P., et al. (2018) Awareness of "Sound" in Nursing Homes: A Large-Scale Soundscape Survey in Flanders (Belgium). Building Acoustics, 25, 43-59. https://doi.org/10.1177/1351010X17748113

[23] Zhao, X., Cheng, B., Liang, S. and Tang, Y. (2009) Design for Human Aural Health: Noise Pollution Prevention and Control in Urban Dwellings Design of China. 3rd International Conference on Bioinformatics and Biomedical Engineering, Beijing, 11-13 June 2009, 1-4. https://doi.org/10.1109/ICBBE.2009.5162590

[24] Dzhambov, A.M. and Dimitrova, D.D. (2014) Urban Green Spaces' Effectiveness as a Psychological Buffer for the Negative Health Impact of Noise Pollution: A Systematic Review. Noise and Health, 16, 157.

https://doi.org/10.4103/1463-1741.134916

[25] Frankenfield, D., Roth-Yousey, L. and Compher, C. (2005) Comparison of Predictive Equations for Resting Metabolic Rate in Healthy Nonobese and Obese Adults: A Systemic Review. Journal of American Dietetic Association, 105, 775-789. https://doi.org/10.1016/j.jada.2005.02.005

[26] Farlex Partner Medical Dictionary (2012). https://medical-dictionary.thefreedictionary.com/DuBois+formula

[27] FEPA (1990) Guidelines and Standards for Environmental Pollution Control in Nigeria. Nigerian Federal Environmental Agency, Nigeria.

[28] Wong, N.H. and Jan, W.L.S. (2003) Total Building Performance Evaluation of Academic Institution in Singapore. Building and Environment, 38, 161-176. https://doi.org/10.1016/S0360-1323(02)00021-5

[29] Shield, B. and Dockrell, J.E. (2004) External and Internal Noise Surveys of London Primary Schools. The Journal of the Acoustical Society of America, 115, 730-738. https://doi.org/10.1121/1.1635837

[30] Aasvang, G.M., Moum, T. and Engdahl, B. (2008) Self-Reported Sleep Disturbances Due to Railway Noise: Exposure-Response Relationships for Nighttime Equivalent and Maximum Noise Levels. The Journal of the Acoustical Society of America, 124, 257-268. https://doi.org/10.1121/1.2932074

[31] Tong, Y.G., Tang, S.K., Kang, J., Fung, A. and Yeung, M.K.L. (2015) Full Scale Field Study of Sound Transmission across Plenum Windows. Applied Acoustics, 89, 244-253. https://doi.org/10.1016/j.apacoust.2014.10.003

[32] Leder, S., Newsham, G.R., Veitch, J.A., Mancini, S. and Charles, K.E. (2015) Effects of Office Environment on Employee Satisfaction: A New Analysis. Building Research \& Information, 44, 34-50. https://doi.org/10.1080/09613218.2014.1003176

[33] Sakellaris, I.A., Saraga, D.E., Mandin, C., Roda, C., Fossati, S., de Kluizenaar, Y., Hänninen, O., et al. (2016) Perceived Indoor Environment and Occupants' Comfort in European "Modern" Office Buildings: The OFFICAIR Study. International Journal of Environmental Research and Public Health, 13, 444. https://doi.org/10.3390/ijerph13050444

[34] Kim, J., de Dear, R., Candido, C., Zhang, H. and Arens, E. (2013) Gender Differences in Office Occupant Perception of Indoor Environmental Quality (IEQ). Building and Environment, 70, 245-256.

https://doi.org/10.1016/j.buildenv.2013.08.022 